Plant Molecular Biology 17: 923-925, 1991.

(C) 1991 Kluwer Academic Publishers. Printed in Belgium.

Update section

Sequence

\title{
Sequence of a tomato gene encoding a third type of LHCII chlorophyll $a / b$-binding polypeptide
}

\author{
Egbert Schwartz, ${ }^{1}$ Robert Stasys, ${ }^{1}$ Ruedi Aebersold, ${ }^{3}$ J. Mitchel McGrath, ${ }^{1}$ Beverley R. Green ${ }^{2}$ and \\ Eran Pichersky ${ }^{1 *}$ \\ ${ }^{1}$ Biology Department, University of Michigan, Ann Arbor, MI 48109, USA (*author for correspondence); \\ ${ }^{2}$ Botany Department, University of British Columbia, Vancouver, B.C., Canada; ${ }^{3}$ Biomedical Research \\ Centre and Department of Biochemistry, University of British Columbia, Vancouver, B.C., Canada
}

Received 31 May 1991; accepted 4 June 1991

Genes encoding two types of chlorophyll $a / b$ binding (CAB) polypeptides localized in the lightharvesting complex (LHCII) of Photosystem II (PSII) have been characterized in a number of plant species (reviewed in $[3,4]$ ). Type I genes contain no introns and encode polypeptides whose mature forms (232-234 residues) migrate on SDS-PAGE with an apparent molecular mass of $26-28 \mathrm{kDa}$. Type II genes contain a single intron and encode polypeptides 2-4 residues shorter than the Type I LHCII polypeptides. The mature Type I and Type II LHCII CAB proteins are approximately $85 \%$ identical in their primary amino acid sequence. In tomato, Type I and Type II correspond to the two major LHCII polypeptides [4, 8; B.R. Green et al., in prep.]. Both types are believed to be phosphorylatable at Thr or Ser residues near the N-terminus [2]. LHCII has a third minor polypeptide of about $25 \mathrm{kDa}$ [6] which is not phosphorylated [1] and is not Nterminally blocked [7]. Morishige and Thornber [7] obtained a 59 residue $\mathrm{N}$-terminal sequence of this protein from barley, which showed that it was distinct from both Type I and II sequences but more related to them than to other CAB polypeptides. They therefore designated it LHCII Type III CAB [7]. Shorter N-terminal sequences identical or almost identical to the barley sequence were also obtained from wheat [10] and maize (R. Bassi, pers. comm.). Comparisons of the Type III N-terminal sequences with the corresponding Type I and II sequences indicate that the $\mathrm{N}$-terminal sequence of the Type III protein is shorter by $7-11$ residues $[7,10]$.

We have isolated and characterized tomato genomic and cDNA clones encoding an LHCII Type III CAB polypeptide (Fig. 1). It is designated cabl3 following our earlier CAB gene nomenclature [9] or $l h b \mathrm{Cl}$ according to the nomenclature proposed by Jansson and Gustafsson [5]. The gene contains two introns (Fig. 1) and resides on chromosome 12 (data not shown). It encodes a precursor polypeptide of 265 residues. $\mathrm{N}$-terminal sequencing of two tomato Type III polypeptides gave the sequence XNDLWYGPDXVXYL.. (identity of $X$ uncertain) which is compatible with Ser as the first residue of the mature protein (Fig. 1). This means that the mature polypeptide encoded by $c a b 13$ has 223 residues and commences with a Ser residue (arrowhead in Fig. 1) not a Gly as reported for the corresponding protein in the other three species. The calculated molecular mass of the mature polypeptide is $24.3 \mathrm{kDa}$. In addition to cabl3

The nucleotide sequence data reported will appear in the EMBL, GenBank and DDBJ Nucleotide Sequence Databases under the accession number $\mathrm{X} 60275$. 


\begin{tabular}{|c|c|}
\hline \\
\hline \multicolumn{2}{|l|}{$\begin{array}{l}\text { TTTTAAAAATCAAGATAGGTGATATAACTTGGAGATATAGTTCATATCTCTTCAAGCCAA } \\
\text { GAGATTGGTTAATCAACACTACACAAAACATCTCCAACCACAATTTCTACTTGTGCAATA }\end{array}$} \\
\hline & \\
\hline CATTTGCCCAAGCACA & \\
\hline TCAATGGCAGCAACAGCTAGCTCCACCACAGTTGTTAAAGCAACACCATTTTTGGGC & \\
\hline $\begin{array}{lllllllllllllllllll}\mathbf{S} & \mathrm{M} & \mathrm{A} & \mathrm{A} & \mathrm{T} & \mathrm{A} & \mathrm{S} & \mathrm{S} & \mathrm{T} & \mathrm{T} & \mathrm{V} & \mathrm{V} & \mathrm{K} & \mathrm{A} & \mathrm{T} & \mathrm{P} & \mathrm{F} & \mathrm{L} & \mathrm{G}\end{array}$ & \\
\hline АССАAAAATGCTAACCCTCTTAGAGATGTTGTTGCCATGGGCTCTGCCAGATTCACCA & \\
\hline $\begin{array}{llllllllllllllllllll}T & \mathrm{~K} & \mathrm{~N} & \mathrm{~A} & \mathrm{~N} & \mathrm{P} & \mathrm{L} & \mathbf{R} & \mathrm{D} & \mathrm{V} & \mathrm{V} & \mathrm{A} & \mathrm{M} & \mathrm{G} & \mathrm{S} & \mathrm{A} & \mathrm{R} & \mathrm{F} & \mathrm{T} & \mathrm{M}\end{array}$ & \\
\hline GTATATATACATTATATTCTCTTTTCTTTTCTCCATGTTTTAGTTTTTATGCTAGTTT & \\
\hline ГCTTGGTATTGCCAAGCTATGGAAACAGTTTCTTGCAGTATCCTTCTCGGACCTCAGAC & \\
\hline АСCTTTTTTTTTCCTTTTCCTACTGG & \\
\hline ГTTTTTCCTCTCATCTTATTAG AGTAATGATTTGTGGTACGGACC TGACCGTGTTAAG & \\
\hline$\downarrow S \quad N \quad D \quad L \quad W \quad Y \quad G \quad P \quad D \quad R \quad V \quad K$ & \\
\hline GCTCAAACT $\overline{C C T T C T T A C T T G A A C G G A G A G T T C C C T G G T G A C ~}$ & \\
\hline $\begin{array}{llllllllllllllllllll} & L & G & P & F & S & A & Q & T & P & S & Y & L & N & G & E & F & P & G & D\end{array}$ & \\
\hline ACGGATGGGACACTGCTGGTTTATCCGCTGATCCCGAGGCCTTTGCCAAGAACAGAGCT & \\
\hline 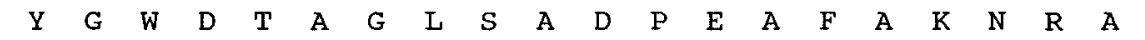 & \\
\hline $\begin{array}{l}\text { TTGAG GTCAGTTATTTGTTCACTCACACTTACCAAAAAGAGAACTAAGATTTGCATAC } \\
\mathrm{L} \quad \mathrm{E}\end{array}$ & \\
\hline ICCTACCTTCCTCAGACGCCACTCATTTTGCTTAGTGACATTGAACTATATAG $\underset{\mathrm{V}}{\mathrm{G} T}$ & \\
\hline AAGATGGGCAATGCTTGGTGCACTA & \\
\hline $\mathrm{R} \quad \mathrm{W} \quad \mathrm{A} \quad \mathrm{M}$ I & \\
\hline TGGGTGAAGGTAGACTTCAAAGAACCAGTATGGTTCAAAGCAGGATCACAAATCTTCAG & 95 \\
\hline $\begin{array}{lllllllllllllllllllll}W & V & K & V & D & F & K & E & P & V & W & F & K & A & G & S & Q & I & F & S\end{array}$ & \\
\hline SACGGTGGACTTGACTACTTGGGAAACCCTAACCTTGTCCATGCTCAGAGTATTCTAGC & \\
\hline 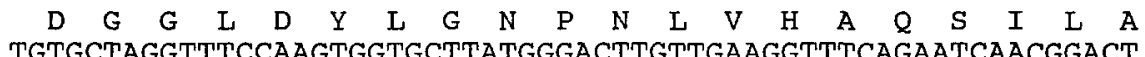 & \\
\hline 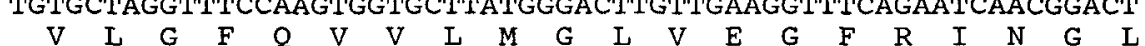 & \\
\hline GAAGGCAACGACTTATACCCCGGT & \\
\hline 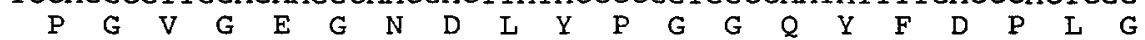 & \\
\hline CTTGCGGATGACCCTACCACATTTGCTGAACTCAAGGTAAAGGAAATCAAAAACGGAAG & \\
\hline $\begin{array}{llllllllll}\text { L } & \text { A } & \text { D } & \text { D } & \text { P } & \text { T }\end{array}$ & \\
\hline GCTATGTTCTCCATGTTTGGATTCTTCGTTCAAGCTATTGTTACCGGTAAAGGCCC & \\
\hline $\begin{array}{llllllllllllllllllll}L & A & M & F & S & M & F & G & F & F & V & Q & A & I & V & T & G & K & G & P\end{array}$ & \\
\hline AACCTATTAGATCACCTTGACAACCCTGTGGCTAAC & \\
\hline $\begin{array}{lllllllllll}L & E & N & I & L & D & H\end{array}$ & \\
\hline ACTAAGTTTGTTCCTGGAGCT TAGATTTATGTTTCAATTCATTGGAAGTACTACCATT & \\
\hline $\begin{array}{llllllll}T & K & F & V & P & G & A\end{array}$ & \\
\hline GTG & \\
\hline & \\
\hline TT & \\
\hline & \\
\hline & \\
\hline & \\
\hline $\mathrm{ACCT}-\mathrm{CT}-\mathrm{A}$ & \\
\hline & \\
\hline
\end{tabular}

Fig. 1. Nucleotide sequence of the tomato $c a b 13$ ( $l h b \mathrm{Cl}$ ) gene. Intron positions were determined by comparing the genomic sequence with the sequence of a full-length cDNA clone. The amino acid sequence is shown below the nucleotide sequence. The peptide sequence obtained from the $\mathrm{N}$-terminus is underlined. The arrow indicates the position of cleavage of the precursor.

(lhbC1), the tomato genome contains at least two other LHCII Type III CAB genes, and all three genes encode almost identical proteins (B.R. Green etal., in prep.). The mature tomato Type III polypeptides are approximately $80 \%$ identical to either the Type I or Type II LHCII $\mathrm{CAB}$ polypeptides.

\section{References}

1. Bassi R, Rigoni F, Barbato R, Giacometti GM: Lightharvesting chlorophyll $\mathrm{a} / \mathrm{b}$ proteins (LHCII) populations in phosphorylated membranes. Biochim Biophys Acta 936: 29-38 (1988).

2. Michel HP, Buvinger WE, Bennet J: Redox control and sequence specificity of a thylakoid kinase. In: Baltscheff- 
sky (ed) Current Research in Photosynthesis, vol 2, pp. 747-753. Kluwer Academic Publishers, Dordrecht (1990).

3. Chitnis PR, Thornber JP: The major light-harvesting complex of Photosystem II: aspects of its molecular and cell biology. Photosyn Res 16: 41-63 (1988).

4. Green BR, Pichersky E, Kloppstech K: Chlorophyll a/bbinding proteins: an extended family. Trends Biochem Sci 16: 181-186 (1991)

5. Jansson S, Gustafsson P: Evolutionary conservation of the chlorophyll $a / b$-binding proteins: cDNA encoding Type I, II and III LHCI polypeptides from the gymnosperm Scots pine. Mol Gen Genet, in press (1991).

6. Machold O: Polypeptide composition of the photosystem I chlorophyll a/b-protein from three different plant species. Carlsberg Res Commun 51: 227-238 (1986).

7. Morishigie DT, Thornber JP: The major light-harvesting chlorophyll $a / b$ protein (LHC IIb): The smallest subunit is a novel CAB gene product. In: Baltscheffsky (ed) Current Research in Photosynthesis, vol 2, pp. 261-264. Kluwer Academic Publishers, Dordrecht (1990).

8. Pichersky E, Hoffman NE, Malik VS, Bernatzky R, Tanksley SD, Szabo L, Cashmore AR. The tomato Cab4 and $C a b-5$ genes encode a second type of CAB polypeptides localized in PS II. Plant Mol Biol 9: 109-120 (1987).

9. Pichersky E, Green BR: The extended family of chlorophyll a/b-binding proteins of PSI and PSII. In: Baltscheffsky (ed), Current Research in Photosynthesis, vol 3, pp. 553-556. Kluwer Academic Publishers, Dordrecht (1990).

10. Webber AN, Gray JC: Detection of calcium binding by photosystem II polypeptides immobilised onto nitrocellulose membrane. FEBS Lett 249: 79-82 (1989). 